\title{
ВЗАИМОСВЯЗЬ ИССЛЕДОВАНИЯ ПСИХОЛОГИЧЕСКОЙ БЕЗОПАСНОСТИ ОБРАЗОВАТЕЛЬНОЙ СРЕДЫ И НЕГАТИВНЫХ КОММУНИКАТИВНЫХ УСТАНОВОК УЧИТЕЛЕЙ
}

\section{THE RELATIONSHIP BETWEEN THE STUDY OF PSYCHOLOGICAL SECURITY OF THE EDUCATIONAL ENVIRONMENT AND NEGATIVE COMMUNICATIVE ATTITUDES OF TEACHERS}

\section{A. Pestov T. Bostanjieva}

Summary: The article presents a study of the relationship between the psychological security of the educational environment and negative communicative attitudes. As a result of the study, we tracked the dynamics in the direction from the initial levels of manifestation of psychological security of the educational environment of the subjects and negative communicative attitudes of teachers. The analysis of empirical manifestations of the dynamics of the study participants is carried out. The results of the study allow us to identify areas for the development and implementation of a developmental program to eliminate negative communicative attitudes among teachers of secondary schools, providing a psychologically safe educational environment.

Keywords: educational environment, psychological security, communicative situation, negative communicative attitude.
Пестов Александр Валерьевич

Аспирант, БУ «Сургутский государственный педагогический университет»

alexq8@mil.ru

Бостанджиева Татьяна Михайловна

К.nсх.н., дочент, БУ «Сургутский государственный педагогический университет»

bost.vi@mail.ru

Аннотация: В статье представлено исследование взаимосвязи психологической безопасности образовательной среды и негативных коммуникативных установок. В результате исследования отслеживалась динамика в направлении от исходных уровней проявления психологической безопасности образовательной среды испытуемых и негативных коммуникативных установок педагогов. Осуществлён анализ эмпирических проявлений динамики участников исследования. Результаты исследования позволяют выделить направления разработки и реализации развивающей программы по устранению негативных коммуникативных установок у учителей общеобразовательной школы, обеспечивая психологически безопасную образовательную среду.

Ключевые слова: образовательная среда, психологическая безопасность, коммуникативная ситуация, негативная коммуникативная установка.
$\mathrm{P}$ еальная педагогическая практика показывает, что довольно четко прослеживается факт потери интереса к собственной профессии, к ученику как к личности, неприятие его таким, какой он есть, упрощение эмоциональной стороны профессионального общения. Тем самым возникает риск развития у учителей негативных коммуникативных установок. Многие педагоги замечают у себя наличие психических состояний, дестабилизирующих профессиональную деятельность, такие как: уныние, тревожность, подавленность, разочарование, хроническая усталость и др., но не придают этому большого значения [5, с. 113].

В связи с нестандартностью психолого-педагогических ситуаций, сложности и ответственности профессионального труда, у многих учителей увеличивается риск развития различных негативных коммуникативных установок, которая влияет на психологическую безопасность образовательной среды.

Под образовательной средой, по мнению В.И. Панова понимается определенная система условий, реализую- щая в своём начале практические технологии и миссии данного образовательного учреждения [7, с. 97].

По мнению И.А. Баевой психологическая безопасность в школьной среде представляет собой обусловленную жизненную успешность и гарантию благополучия ребенка, в котором учителя и родители делают, есть акцент на формирование положительной и успешной личности в образовательной среде [1, с. 104].

Понятие коммуникативной удачи и неудачи применяется ко всей коммуникативной ситуации, тем самым изменение коммуникативной удачи и неудачи в образовательной среде ведет к модификации коммуникативной ситуации и тем самым к варьированию средств, используемых участниками ситуации, и их коммуникативного поведения в целом [4, с.113].

Необходимо отметить, что обращение к школьной коммуникации, и в частности к такому аспекту, как ответ на вопрос учителя, показывает, несоответствие ожидаемых результатов одного из участников коммуникации, 
например, учителя, оборачивается для другого, т.е. ученика коммуникативной неудачей, который имеет соответствующее оценочное выражение [3, с. 6].

Таким образом, важнейшей психолого-педагогической задачей образования является создание такой образовательной среды, которая отвечала бы всем требованиям для создания комфортной и безопасной среды для обучающихся, родителей и преподавателей в аспекте сохранения и преумножения физического и психического здоровья [2, с. 67].

Для проведения исследования мы использовали методику «Психологическая диагностика образовательной среды» по И.А. Баевой [6, с. 118], методику «Диагностика коммуникативной установки» по В.В. Бойко [8]. Эмпирическое исследование проводилось на базе средней общеобразовательной школы г. Сургута Тюменской области. В исследовании приняли участие - 88 учителей средней общеобразовательной школы.

Представим результаты исследования по методике «Психологическая диагностика образовательной среды» И.А. Баевой. Результаты исследования представлены в таблице 1.

Таблица 1

Выраженность компонентов отношения учителей к образовательной среде школы

\begin{tabular}{|l|c|c|}
\hline $\begin{array}{l}\text { Компоненты отношения к } \\
\text { образовательной среде }\end{array}$ & $\begin{array}{l}\text { Учителя началь- } \\
\text { ных классов (\%) }\end{array}$ & $\begin{array}{l}\text { Учителя среднего } \\
\text { звена (\%) }\end{array}$ \\
\hline Эмоциональный & 40,3 & 40,5 \\
\hline Когнитивный & $\mathbf{8 7 , 7}$ & $\mathbf{8 7 , 8}$ \\
\hline Поведенческий & 50,2 & 53,1 \\
\hline Когнитивно-эмоциональный & $\mathbf{6 6 , 5}$ & $\mathbf{7 1 , 7}$ \\
\hline Эмоционально-поведенческий & 35,7 & 38,5 \\
\hline Все три компонента & 56,0 & 58,3 \\
\hline
\end{tabular}

Анализ полученных данных показал, что в большей степени в образовательной среде преобладает когнитивный компонент у учителей начальных классов $(87,7)$ и учителей среднего звена $(87,8)$. Данный результат свидетельствует о том, что когнитивный или рациональный компонент в образовательной среде подразумевает наличием у педагогов осведомленности об образовательной среде, знаний и её роли в обществе. Самые низкие показатели отношения к образовательной среде выявлены в эмоционально-поведенческом компоненте, у учителей начальных классов $(35,7)$, у учителей средних классов $(38,5)$. Данный результат связан с тем, у учителей данной категории слабо развито умение управлять своим поведением и других участников образовательного процесса, также слабо развиты эмоционально-волевые качества, которые имеют место в проявлении отрица- тельных эмоций по отношению к учебному процессу и образовательной среды в целом.

Представим результаты исследования по методике «Диагностика коммуникативной установки» В.В. Бойко. Общий уровень не должен превышать 33 процентов, иначе можно говорить о наличии выраженной негативной коммуникативной установки у учителей. Результаты исследования представлены в таблице 2.

Таблица 2

Выраженность компонентов негативной коммуникативной установки учителей

\begin{tabular}{|c|c|c|}
\hline $\begin{array}{l}\text { Компоненты негативной комму- } \\
\text { никативной установки }\end{array}$ & $\begin{array}{l}\text { Учителя началь- } \\
\text { ных классов (\%) }\end{array}$ & $\begin{array}{l}\text { Учителя среднего } \\
\text { звена (\%) }\end{array}$ \\
\hline Завуалированная жестокость & 49,7 & 54,9 \\
\hline Открытая жестокость & 57,5 & 31,6 \\
\hline Обоснованный негативизм & 49,3 & 32,4 \\
\hline Брюзжание & 32,2 & 45,1 \\
\hline Негативный опыт общения & 32,4 & 39,0 \\
\hline $\begin{array}{l}\text { Общий уровень негативной ком- } \\
\text { муникативной установки }\end{array}$ & 44,2 & 40,6 \\
\hline
\end{tabular}

Анализ полученных данных показал, что в общий уровень негативной коммуникативной установки у всех учителей проявился на среднем уровне. Результат свидетельствует о том, что негативная коммуникативная установка учителей может повлиять на неблагоприятное самочувствие учеников, на проявление открытой жесткости со стороны учеников так и со стороны учителей, не толерантность в коммуникативной сфере и завуалированная жесткость со стороны учителей.

Подводя итог, можем отметить, что насыщение образовательной среды мероприятиями, которые могут вызывать у учащихся подлинные положительные эмоции задача администрации учебных заведений, а доведение до нее этой задачи - является частью работы психологической службы.

Анализ взаимосвязи компонентов негативной коммуникативной установки и психологических характеристик школьной образовательной среды учителей начальных классов показал следующие связи: показатель «открытая жестокость» имеет одну обратную взаимосвязь с показателем «эмоционально-поведенческий компонент отношения к образовательной среде» ( $\mathrm{r}=-$ 0,22319; $p<0,05)$. Данный показатель свидетельствуют о том, что чем сильнее учителя начальных классов проявляют открытую жесткость по отношению к окружающим, не скрывая свои негативные оценки, тем слабее у них развито умение управлять своим поведением и других участников образовательного процесса, также слабо развиты эмоционально-волевые качества, которые име- 
ют место в проявлении отрицательных эмоций в отношении школы, учебного процесса и образовательной среды в целом.

Анализ взаимосвязи компонентов негативной коммуникативной установки и психологических характеристик школьной образовательной среды учителей средних классов показал следующие связи: показатель «негативный опыт общения» имеет одну обратную взаимосвязь с показателем «когнитивный компонент отношения к образовательной среде» $(r=-0,21989 ; p<0,05)$. Данный показатель свидетельствуют о том, что чем сильнее учителя средних классов проявляют недоверие по отношению к профефссииональному и коммуникативному опыту своих коллег, близкого круга общения при взаимодействии в профессиоальном плане, тем хуже учителя данной категории осведомленными об образовательной среде, знаний и её роли в обществе.

Таким образом, анализ взаимосвязи компонентов негативной коммуникативной установки и психологических характеристик школьной образовательной среды показал, что большинство учителей всех категорий в коллективе испытывают психологический дискомфорт в образовательном процессе; утрату доверия к себе и к коллективу; неудовлетворенность образовательной средой, связанный с эмоциональным и физическим напряжением; недостаточное взаимопонимание, доверие и доброжелательное отношение. Также негативные показатели связаны с тем, что у учителей не всегда имеется возможность обратиться за помощью, что предполагает недостаточное уважительное отношение к образовательной среде.

Обобщая результаты исследования, необходимо отметить, что важнейшей задачей для педагогической системы является, с одной стороны, насыщение образовательной среды мероприятиями, которые обеспечивают для учащихся переживание подлинных положительных эмоций, а с другой стороны, проведение тренингов, и мероприятий психолого-педагогической коррекции, которые приведут к снижению доли отрицательных эмоций.

Таким образом, при реализации программы психологического сопровождения учителей по профилактике негативных коммуникативных установок и улучшению компонентов отношения к образовательной среде будет способствовать снижению таких показателей, как: «когнитивно-эмоциональный» компонент отношения к образовательной среде, «завуалированная жестокость», «открытая жестокость». Намеченные направления работы могут лечь в основу специальных практико-ориентированных курсов, которые дадут возможность учителям развить профессионально значимые качества.

\section{ЛИТЕРАТУРА}

1. Баева И.А. Обеспечение психологической безопасности в образовательном учреждении / И.А. Баева. - СПб. : Речь, Серия: Современный учебник, 2006. - C. 104.

2. Березина Т.Н. Формирование эмоциональной безопасности образовательной среды (психолого-педагогические аспекты) // Современное образование. $-2015 .-$ № 1. - С. 67.

3. Городецкий Б.Ю. Компьютерная лингвистика: моделирование языкового общения // Новое в зарубежной лингвистике. М.: Наука, 1989. Вып. 24. — С. 6.

4. Гусева Е.Н. Коммуникативные неудачи в системе «учитель-ученик» // Вестник РМАТ. — 2013. — № 4. — С. 113.

5. Михайлова В.П. Проблема эмоционального «выгорания» и свойства личности / В.П. Михайлова, Т.И. Кувшинова, Н.И. Корытченкова // Проблемы исследования синдрома «выгорания» и пути его коррекции у специалистов «помогающих» профессий: Сб. науч. ст. - Курск : КГУ, 2007. - С. 113.

6. Обеспечение психологической безопасности в образовательном учреждении / Под ред. И.А. Баевой. - СПб.: Речь, 2006. - 288 с. - С. 118.

7. Панов В.И. Психодидактика образовательных систем: теория и практика / В.И. Панов. - СПб. : Питер, 2007. - С. 97.

8. Райгородский Д.Я. Практическая психодиагностика. Методики и тесты. Учебное пособие. - Самара: Бахрат, 1998. - 672 с. 